4 Chung CK, Stryker JA, Cruse R, Vanucci R, Twofighi J. Glioblastoma multiforme childing prophylactic cranial irradiation and intrathecal methotrexate in a child with acute lymphoblastic leukaemia. Cancer 1981;47:2563-6.

5 Anderson JR, Treip CS. Radiation-induced intracranial neoplasms. Cancer $1984 ; 53: 426-9$.

(Accepted 24 fuly 1984)

Royal Hospital for Sick Children, Edinburgh EH9 1LF

MARY R JUDGE, MRCP, registrar in haematology

O B EDEN, FRCPED, consultant haematologist

Royal Infirmary, Edinburgh EH3 9YW

PATRICK O'NEILL, FRCSI, registrar in neurosurgery

Correspondence to: Dr O B Eden, Department of Haematology, Royal Hospital for Sick Children, Sciences Road, Edinburgh EH9 1LF.

\section{Proliferative glomerulonephritis associated with Crohn's disease}

Extraintestinal manifestations of inflammatory bowel disease are well described and can affect many systems. The suggestion has arisen that circulating immune complexes may be connected with some of these complications, and hence it might be expected that renal complications would be a recognised extraintestinal feature.

\section{Case report}

A 49 year old woman presented with a three month history of lowe abdominal pain, frequency of micturition, and nocturia. Abdominal examination showed a mass in the right iliac fossa. Blood pressure was $120 / 80 \mathrm{~mm} \mathrm{Hg}$ Her urine contained albumin $++t$ and blood + . Haemoglobin concentration was $13.3 \mathrm{~g} / \mathrm{dl}$, urea $7.8 \mathrm{mmol} / 1(46.8 \mathrm{mg} / 100 \mathrm{ml})$, and creatinine $0.12 \mathrm{mmol} / 1(1.4 \mathrm{mg} / 100 \mathrm{ml})$, and normal results were obtained on intravenous urography and cystoscopy and on barium enema, at which contrast refluxed into the terminal ileum. She had a coliform urinary tract infection, and treatment with antibiotics produced symptomatic improvement.

Nine months after her initial presentation her blood pressure was 200 $115 \mathrm{~mm} \mathrm{Hg}$. During this period she had been tired and anorectic, lost $8 \mathrm{~kg}$ in weight, and had occasional pains in the right iliac fossa. Further investigations showed haemoglobin concentration $11.9 \mathrm{~g} / \mathrm{dl}$; erythrocyte sedimentation rate $38 \mathrm{~mm}$ in the first hour; urea $13.3 \mathrm{mmol} / 1(79.9 \mathrm{mg} / 100 \mathrm{ml})$ creatinine $0.20 \mathrm{mmol} / 1(2.3 \mathrm{mg} / 100 \mathrm{ml})$; calcium and phosphate concentrations and alkaline phosphatase activity normal; serum albumin $28 \mathrm{~g} /$ (normal $33-48 \mathrm{~g} / \mathrm{l}$ ); creatinine clearance $28 \mathrm{ml} / \mathrm{min} ; 24$ hour urinary protein excretion $3.43 \mathrm{~g}$ (unselective); serum IgG $4 \cdot 2 \mathrm{~g} / 1$ (normal $8-16 \mathrm{~g} / \mathrm{l}$ ), $\mathrm{IgA}$ $0 \cdot 2 \mathrm{~g} / 1$ (normal $1 \cdot 2-4 \cdot 0 \mathrm{~g} / \mathrm{l}$ ), and $\operatorname{IgM} 0 \cdot 3 \mathrm{~g} / 1$ (normal $0 \cdot 5-1.6 \mathrm{~g} / \mathrm{l}$ ); and norma serum complement concentrations. Tests for antinuclear factor and latex and sheep cell agglutination tests yielded negative results.

Her hypertension was treated and renal biopsy performed. Histological examination showed several glomeruli with extensive sclerosis; others wer enlarged with hypercellularity associated with expansion of the mesangial areas and sclerosis (figure). Immunofluorescence showed focal peripheral deposition of $\operatorname{IgG}, \mathrm{IgM}$, and fibrinogen. $\mathrm{IgA}, \mathrm{C} 3$, and $\mathrm{Clq}$ were absent The glomeruli examined by electron microscopy were largely sclerotic and essentially unhelpful. Interpretation of the renal biopsy was difficult, but the

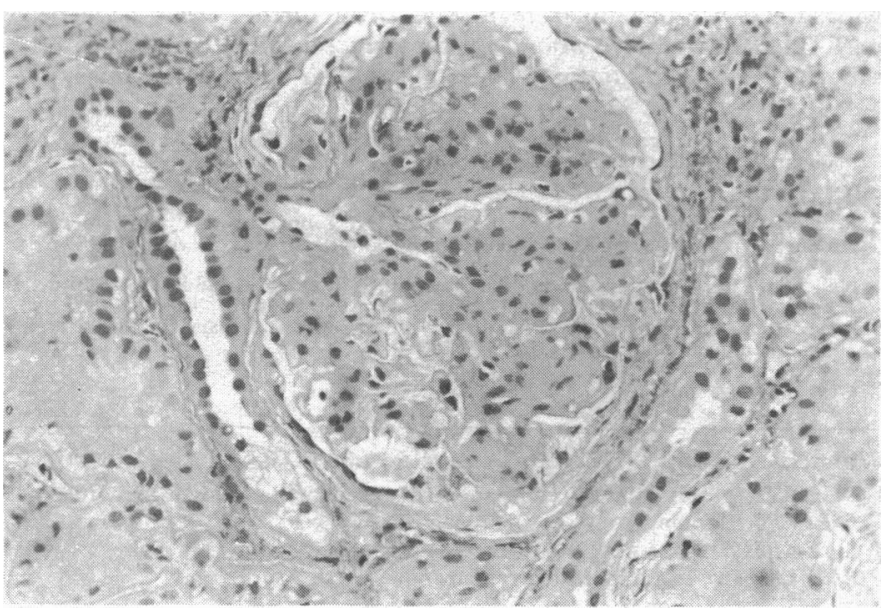

Glomerulus showing mesangial hypercellularity with sclerosis. $\times 258$. most likely diagnosis was mesangial proliferative glomerulonephritis with sclerosis. After renal biopsy she developed abdominal pain, vomiting, and abdominal distension. Laparotomy showed gross Crohn's disease affecting only the terminal ileum, and this was confirmed by histological examination. A right hemicolectomy with ileal resection was performed.

Over the 12 months after operation she felt well and gained over $5 \mathrm{~kg}$ in weight. Her serum albumin concentration was normal; creatinine $0 \cdot 17$ $0 \cdot 19 \mathrm{mmol} / 1(1 \cdot 9-2 \cdot 1 \mathrm{mg} / 100 \mathrm{ml})$; creatinine clearance $26-32 \mathrm{ml} / \mathrm{min}$; and 24 hour urinary protein excretion $2 \cdot 2-4 \cdot 9 \mathrm{~g}$. Circulating immune complexes were measured before and after the operation. Although $\mathrm{C}_{3}$ and $\mathrm{Clq}$ complexes were raised, there was no significant difference in the values before and after resection.

\section{Comment}

The association between Crohn's disease and glomerulonephritis seems rare. We have found only one reported case. ${ }^{1}$ Four cases of glomerulonephritis associated with ulcerative colitis have been reported. ${ }^{2-4}$

Although it has been suggested that the glomerular lesions seen in the above cases were secondary to deposition of immune complexes, no immune complexes were shown in the serum. In our case immune complexes were found but the concentrations were not strikingly high and remained unchanged after operation. Interestingly, experimental evidence suggests that inoculation of lymph node or intestinal tissue from patients with Crohn's disease can induce glomerular immune complexes in mice deficient in $\mathrm{T}$ cells. ${ }^{5}$

In our case symptoms and signs of Crohn's disease had been present for at least nine months before renal biopsy and laparotomy. During this period there was persistent proteinuria and haematuria, the patient developed hypertension, and renal function deteriorated considerably. After resection renal function did not deteriorate further There seems to be some circumstantial evidence that the glomerulonephritis was directly associated with the Crohn's disease. Our case possibly represents one end of a range of glomerular changes occurring in patients with inflammatory bowel disease, which are usually not clinically evident.

We thank Dr J C Leonard, Dr P J Whorwell, and Dr A M Lessells for their help in producing this paper.

I Dyduch J, Kucharska K, Depowski M, Sancewicz-Pach K. Crohn's disease with chronic glomerulonephritis in a boy aged 14 years. Pol Tyg Lek 1976;31:2025-6. Stokke KT, Teisberg PA, Myhre E, Hovig T, Flatmark A, Gjone E. Nephrotic syndrome in ulcerative colitis. Scand 7 Gastroenterol 1976;11:571-6. Nephrotic Hellwege HH, Blaker F, Gebbers JO. Hypocomplementaemic membranoproliferative glomerulonephritis in a child with ulcerative colitis. Monatsschr Kinderheilkd 1976;124:706-11.

4 Aguglia F, Santucci A, Faraggiana T, Di Pietro N. Focal and segmental glomerula sclerosis in the course of ulcerative colitis. Clin Ter 1979;91:197-202.

5 Williams SE, Valenzuela I, Kadish AS, Das KM. Glomerular immune complex formation and induction of lymphoma in athymic nude mice by tissue filtrates

(Accepted 31 fuly 1984)

University Hospital of South Manchester, Manchester M20 8LR $P$ M SCHOFIELD, MRCP, senior house officer in medicine P S WILLIAMS, MRCP, registrar in medicine

Correspondence to: Dr P M Schofield, St Mary's Hospital, London W2 1 NY.

\section{Algorithm for modified alkaline diuresis in salicylate poisoning}

The use of forced alkaline diuresis in patients poisoned with salicylate is well established. Even in fit young patients, however, such treatment may cause fluid overload ${ }^{1}$ or death. ${ }^{2}$ Prescott et al showed that alkali alone removed salicylate at least as effectively as conventional forced alkaline diuresis, but the optimum treatment regimen had still to be determined. ${ }^{3}$ In the light of this we devised an algorithm for modified alkaline diuresis that has proved effective and simple to administer and has much less risk of producing an overload of fluid (figure). We report its use in six patients.

\section{Patients, methods, and results}

The regimen was used in six patients (aged 19-69) with no history of cardiovascular or renal disease or clinical evidence of heart failure. The fluids used contained $1 \cdot 26 \%$ sodium bicarbonate and $5 \%$ dextrose. Sodium 